\title{
The Socio-economic Determinants of Antenatal Health Care Utilization in Bangladesh: Evidence from Multivariate Techniques
}

\author{
Ahbab Mohammad Fazle Rabbi ${ }^{1}$ and Shamal Chandra Karmaker ${ }^{2 *}$ \\ ${ }^{1}$ Department of Applied Science, Bangladesh University of Textiles; Dhaka-1208, Bangladesh \\ ${ }^{2}$ Department of Statistics, Biostatistics and Informatics, Dhaka University, Dhaka-1000, Bangladesh
}

(Received : 13 March 2014 2014; Accepted : 5 August 2014)

\begin{abstract}
The results presented in this study examined factors associated with antenatal care seeking behaviour using the data of BDHS-2007. Multivariate techniques were applied to identify significant determinant of ANC utilization by women in Bangladesh. Five factors have been determined by using factor analyses and these factors are considered as underlying reasons behind ANC seeking behaviour. One of these factors is biological and the remaining ones are socio-economical. Linear discriminant analysis explained the competence of factors identified in this study. These five factors are considered accurate for approximately 70 percent of the observations. It is expected that the results presented in this study will help to formulate better policies and program interventions to enhance the ANC seeking behaviour of women in Bangladesh.
\end{abstract}

Key words: ANC seeking behavior, Multivariate techniques.

\section{Introduction}

According to the World Health Organization (WHO), maternal mortality as well as associated maternal morbidity is a serious public health concern for Bangladesh. Appropriate antenatal care services promote safe-motherhood and decrease the likelihood of neonatal and infant mortality. The WHO reports $\left(\mathrm{WHO}^{1} 2010\right)$ that on an average half a million women face untimely death due to complications during pregnancy as well as at the time of childbirth or after six weeks following delivery. It has also been reported that $99 \%$ of these deaths occur in developing countries. Reproductive health is a priority program for all the Southeast Asia Regional countries. To prevent undesirable outcomes of pregnancy, antenatal care (ANC) is considered to be the most essential process to identify pregnancy related problems in the early period (Nurainiand Parker $^{2}, 2007$ ). ANC utilization is a critical element for reducing maternal mortality and morbidity; and for providing pregnant women with a wide range of health promotion and preventive health services. Another crucial function of ANC is to offer health information and services that can significantly improve the health of women and their infants (Carroliet. al. ${ }^{3}$, 2001).

As a developing country, Bangladesh also suffers from the problem of maternal morbidity; although significant successes have been achieved in Bangladesh in last decade $\left(\mathrm{WHO}^{1}\right.$ 2010). Extensive research have been carried out to understand the influence of the socio-economic and cultural environment on individual ANC seeking behavior for Bangladesh, while adjusting for individual and household-level factors (Pickett and Pearl ${ }^{4}, 2001$; Say and Raine ${ }^{6}, 2007 ;$ Khatun and Rahman ${ }^{6}$, 2008;Anwar et.al. ${ }^{7}, 2008$;Pervin et.al. ${ }^{8}, 2012$ ). The education level of parent's, labor force participation of mother, community based differentiation (both regional and rural affect), previous and index parity report were found as significant differential of ANC seeking behavior (Amin et. al. ${ }^{9}, 1989$; Pickett and Pearl $^{4}, 2001$; Simkhada et. al. ${ }^{10}, 2008$; Anwar et. al. ${ }^{7}, 2008$; Islam and Odland $\left.{ }^{11}, 2011\right)$. Logistical barriers to seeking ANC for women are critical for those in communities with higher socio-economic status and a more developed health infrastructure. However, the presence of health facilities in a community alone does not essentially result in enhancing utilization (Choudhury and Ahmed ${ }^{12}$, 2011; Stephensonand Elfstrom ${ }^{13}$, 2012).Women's autonomy is described as key factor behind maternal health care seeking prospects, though its determinants are analogous as that of ANC seeking behavior (Woldemicael ${ }^{14}, 2009$ ). Almost same differentials are obtained for ANC seeking behavior in developing countries and other countries where demographic surveillance system exist (Dynes et. al. ${ }^{15}$, 2011;Rahman et. al. $\left.{ }^{16}, 2011\right)$.

While searching for differentials of ANC seeking behavior for a developing country, use of multivariate technique is most common tools for researchers, though it creates some difficulties in explanation, too (Say and Raine $\left.{ }^{6}, 2007\right)$. For example, the most common differentials for ANC seeking behavior described above does not work alone for increase/decrease ANC seeking behavior, but confound with others relative determinants which act like a common factor to increase/decrease ANC seeking behavior. Instead of searching for individual differentials few studies also suggest for separate model to obtain determinants of ANC seeking behavior for a developing country (Rahman et. al. ${ }^{16}, 2011$; Akanda $^{17}$, 2009). Another complication arises from usual multivariate analysis is the problem of multicollinearity. For example, the educational and labor force participation variables are highly correlated for parents of developing countries, also there are presence of correlation between socio-economic status and women's autonomy (Anwar et. al. ${ }^{7}, 2008$ ).

The present study mainly emphasises on obtaining the underlying factor behind ANC seeking behavior of women of Bangladesh, instead of searching for individual differentials. The significance behind using these techniques are simplicity of explanation and explaining the confounded effect of several determinants together which was not so rigidly possible in case of usual multivariate regression

*Author for Correspondence.e-mail: sck_stat@du.ac.bd 
models. There are two part of the current analysis- at first factor analysis will be carried out to obtain significant factor of ANC seeking behaviour followed by linear discriminant analysis to verify the factors obtained as a result of factors analysis.

\section{Data and Methodology}

Secondary data received from Bangladesh Demographic and Health Survey (BDHS-2007) was used for current study. The BDHS is a nationally representative survey was conducted under the authority of the National Institute for Population, Research and Training (NIPORT) of the Ministry of Health and Welfare, Bangladesh and funded by USAID. Health and demographic data of 10996 ever married women of reproductive age obtained using multistage cluster sampling. The WHO standard for ANC is at least 4 ANC visit, BDHS-2007 indicates 60 percent of women with a birth in the five years preceding the survey received antenatal care at least once from any provider, while 52 percent received care from a medically trained provider.

Principal Component Analysis was used for extraction of factors and orthogonal rotation (varimax option) was used to obtain non-correlated factors (Hair et. al. ${ }^{18}$, 1995). This varimax method attempts to diminish the number of indicators that have high loading on single factor (Mardia et. al. $\left.{ }^{19}, 1980\right)$. Kaiser criterion is used for the choice of the number of factors in factor analysis (Eigen value of $>1.0$ ) which was also based on the Eigen plot (scree plot). Scree plot also shows the total variance associated with each other. Linear discriminant function analysis was carried out using the factor scores derived through the factor analysis to determine as to how correctly mothers having/not having ANC are correctly classified.

Table 1. Rotated Component Matrix for ANC seeking behavior of Bangladeshi women (BDHS-2007).

\begin{tabular}{|l|c|c|c|c|c|}
\hline \multirow{2}{*}{\multicolumn{1}{c|}{ Variable }} & \multicolumn{3}{c|}{ Component } \\
\cline { 2 - 7 } & $\mathbf{1}$ & $\mathbf{2}$ & $\mathbf{3}$ & $\mathbf{4}$ & $\mathbf{5}$ \\
\hline Age (5-year groups) & 0.028 & 0.895 & 0.051 & -0.042 & -0.008 \\
\hline Division & 0.009 & 0.040 & 0.030 & 0.002 & 0.918 \\
\hline Type of place of residence & -0.629 & -0.146 & 0.017 & -0.211 & -0.090 \\
\hline Highest educational level & 0.652 & -0.375 & 0.096 & -0.172 & -0.195 \\
\hline Wealth index & 0.854 & -0.009 & 0.040 & -0.137 & 0.053 \\
\hline Mass media exposure status & 0.744 & -0.108 & 0.053 & 0.111 & 0.051 \\
\hline Mother's employment status & -0.085 & 0.021 & 0.068 & 0.600 & 0.033 \\
\hline Father's education level & 0.691 & -0.166 & 0.086 & -0.252 & -0.192 \\
\hline Birth order of index child & -0.248 & 0.866 & -0.029 & 0.038 & 0.021 \\
\hline Final say on own health care & 0.060 & 0.035 & 0.852 & -0.023 & -0.010 \\
\hline Final say on child health care & 0.066 & -0.003 & 0.851 & 0.102 & -0.001 \\
\hline $\begin{array}{l}\text { Discussed about family planning with } \\
\text { partner }\end{array}$ & 0.226 & -0.187 & -0.009 & 0.419 & -0.002 \\
\hline Goes to a health centre or hospital alone & 0.068 & 0.312 & 0.776 & 0.370 & -0.335 \\
\hline Connection to NGO (binary) & -0.127 & 0.087 & -0.023 & 0.674 & -0.039 \\
\hline
\end{tabular}

Extraction Method: Principal Component Analysis.

Rotation Method: Varimax with Kaiser Normalization.

Rotation converged in 5 iterations.

\section{Results}

According to previous studies, both socio-demographic and proximate covariates are possible determinant of ANC seeking behavior (Islam and Odland ${ }^{11}, 2011$ ). Obviously, the strength and direction of all covariates will not be same; and some of them work through other variables, too. In this context, first step of current study is to search for significant factor and then to find the direction of covariates from that dominant factor. Figure 1 presents the scree plot of factor analysis for ANC seeking behavior of Bangladeshi women. The adequacy of data was evaluated based on the value of $\mathrm{KMO}$ and homogeneity of variance; the parallel line to horizontal at Eigen value equaling to one in scree plot are the significant factors for ANC seeking behavior of Bangladeshi women.

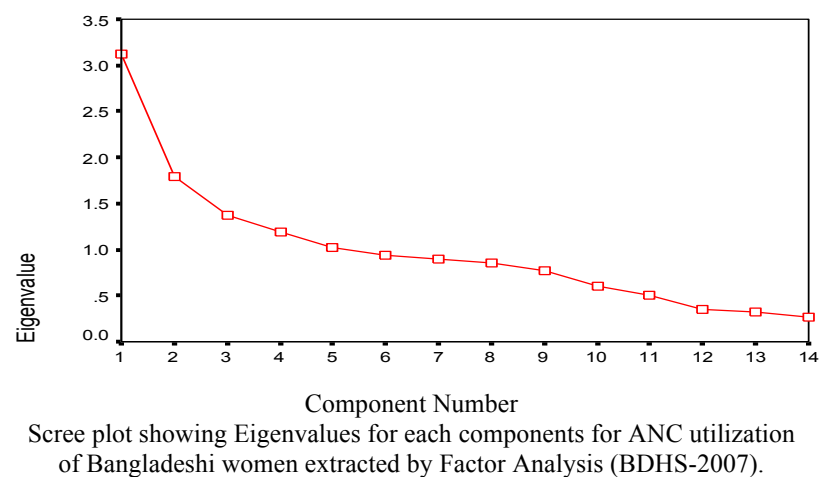

Fig. 1. Factors behind ANC seeking behavior of Bangladeshi women (BDHS-2007).

Rotated component matrix of factor analysis is presented in the Table 1. Here the components are the significant obtained from PCA, and the factors are named later according to the value of loadings and cross-loadings described in methodology section. 
Factor analysis obtained total 14 components, from which only 5 components were significant according to Kaiser Criterion. The components are numbered in ascending scale according to amount of variance explained. Obtained factors are quite hypothetical in nature, as the factors are obtained from several types of socio-economical, biological and birth history variables. These five factors extracted from factor analysis, explain the variation of ANC seeking behavior of
Bangladeshi women by $22.276,12.809,9.777,8.492,7.308$ percentages respectively. These factors can explain about $60.66 \%$ of the observed variation in the possible socioeconomical/health/biological variables determining ANC seeking behavior of Bangladeshi women (Table-2). Table 2 illustrates the eigenvalues, percentage of variation explained by each eigenvalue and the cumulative percentage of variation explained by those eigenvalues.

Table 2. Total Variance Explained by the obtained factors of ANC seeking behavior of Bangladeshi women (BDHS-2007).

\begin{tabular}{|c|c|c|c|c|c|c|c|c|c|}
\hline \multirow{2}{*}{ Component } & \multicolumn{4}{|c|}{ Initial Eigenvalues } & \multicolumn{3}{c|}{ Extraction Sums of Squared } & \multicolumn{3}{c|}{ Loadings } & \multicolumn{3}{c|}{ Rotation Sums of Squared Loadings } \\
\hline & Total & $\begin{array}{c}\text { \% of } \\
\text { Variance }\end{array}$ & $\begin{array}{c}\text { Cumulative } \\
\%\end{array}$ & Total & $\begin{array}{c}\text { \% of } \\
\text { Variance }\end{array}$ & $\begin{array}{c}\text { Cumulative } \\
\%\end{array}$ & \multicolumn{2}{c|}{$\begin{array}{c}\text { Total } \\
\text { Variance }\end{array}$} & $\begin{array}{c}\text { Cumulative } \\
\%\end{array}$ \\
\hline 1 & 3.119 & 22.276 & 22.276 & 3.119 & 22.276 & 22.276 & 2.731 & 19.506 & 19.506 \\
\hline 2 & 1.793 & 12.809 & 35.085 & 1.793 & 12.809 & 35.085 & 1.895 & 13.538 & 33.044 \\
\hline 3 & 1.369 & 9.777 & 44.861 & 1.369 & 9.777 & 44.861 & 1.511 & 10.796 & 43.840 \\
\hline 4 & 1.189 & 8.492 & 53.353 & 1.189 & 8.492 & 53.353 & 1.309 & 9.351 & 53.191 \\
\hline 5 & 1.023 & 7.308 & 60.661 & 1.023 & 7.308 & 60.661 & 1.046 & 7.470 & 60.661 \\
\hline
\end{tabular}

The first extracted factor (the factor which explained highest variation) have high factor loadings (positively correlated) with parental education, wealth index, mass media exposure status of mother and high cross loadings (negatively correlated) with place of residence. These variables are significant determinants in previous studies, too (Rahman et $\mathrm{al}^{16}$ 2011). With increase of educational level and mass media coverage ANC seeking behavior increases, also the rural people are lower ANC seeker than urban women whichisassociated as level of consciousness about ANC (Rahman et. al. ${ }^{16}, 2011$ ). So, we are naming this factor as 'Consciousness factor'. Mother's age, reproductive life spent before index child are explained as key determinant of ANC seeking behavior in other study; we also have same result. Previous studies also showed that, ANC seeking behavior increase with mother's age (Khatun and Rahman ${ }^{6}$, 2008). Second factor have high loadings with mother's age and birth order of index child. We may name this factor as 'Age and reproductive experience factor'. This factor is important for family planning researcher because previous studies also showed the increment in level of ANC seeking behavior with higher parity (Anwar et. al. ${ }^{7}, 2008$ ).

In under-developed and developing countries, women's empowerment and rising of autonomy has vast research interest in recent era, as autonomy has direct causal relation with maternal health care seeking behavior also play the role of proximate determinant for ANC seeking behavior (Woldemicael ${ }^{14}$, 2009). Third obtained factor from factor analysis have high factor loadings with freedom of movement and say about own and child health care of mothers. These variables are key indicators of women's empowerment, that's why we are naming this factor as 'Autonomy factor'. Fourth factor have high loadings with employment status of mother and connection with microcredit programs, namely NGOs'. We are naming this factor as 'Mother's involvement with labor force participation factor'. Employment status (self/with NGO) have significant effect on maternal health care utilization, which have been described precisely in many previous studies (Choudhury and Ahmed ${ }^{12}$, 2011; Stephenson and Elfstrom $\left.^{13}, 2012\right)$. The third and fourth factor have some crossings in few points, as there are linkage of economical solvency and/or question of achieving autonomy from income generating activities of women. These intersects had been explained elaborately in previous study (Woldemicael $^{20}, 2009$ ). The fifth extracted factor has high factor loading with divisions. BDHS-2007 report also stated that, ANC seeking behavior is not same for all the divisions of Bangladesh, highest is observed in Khulna division $(62.6 \%)$ and lowest is observed in Sylhet division (46.9\%). So, we may name this factor as 'Regional difference factor'.

Linear discriminant function analysis was used for studying the relationship between the explored factors in factor analysis and ANC seeking behavior of Bangladeshi women, the results is presented in table 3 . The factor scores obtained by the factor analysis were considered continuous independent variables, and ANC seeking behavior was considered dichotomous dependent variable. Two groups are considered for this analysis, have ANC and not have ANC for the index child. The reason behind such groupings is to avoid computational complexity. 
Table 3. Classification of individual mothers using scores derived from factor analysis for ANC seeking behavior of Bangladeshi women (BDHS-2007).

\begin{tabular}{|c|c|c|c|c|c|}
\hline & & Frequency of anc & \multicolumn{2}{|c|}{ Predicted Group Membership } & Total \\
\cline { 4 - 6 } & & visit (binary) & None & Have ANC & \\
\hline Original & Count & None & 1740 & 686 & 2426 \\
\hline & & Have ANC & 430 & 907 & 1337 \\
\hline & $\%$ & None & 71.7 & 28.3 & 100.0 \\
\hline & & Have ANC & 32.2 & 67.8 & 100.0 \\
\hline
\end{tabular}

$70.3 \%$ of original grouped cases correctly classified.

Based on the results of linear discriminant function, overall $70.3 \%$ of the ANC seeking behavior of Bangladeshi women was predicted correctly. For mothers who didn't have ANC, $71.7 \%$ of the mothers were classified correctly; while for other mothers (have ANC), 67.8\% observations were correctly classified. In other words, sensitivity of discriminant function was $71.7 \%$ and the specificity was $67.8 \%$.

\section{Conclusions}

Globally, half a million of women die every year from pregnancy and childbirth related obstacles, over $90 \%$ of these deaths happen in developing countries, including Bangladesh $\left(\mathrm{WHO}^{1}, 2010\right)$. Therefore, study of differentials of ANC utilization enables the researchers and policymakers to gain better ideology on current scenario of ANC utilization for a country. The objective of the current study is to obtain underlying factor behind ANC seeking behavior for Bangladesh.

Few findings of the current study are like previous studies, while others are not; as main emphasis is given to obtain underlying factor behind ANC utilization rather than separate effect of each determinants (Akanda ${ }^{17}$, 2009; Rahman et. al. ${ }^{16}$, 2011;). Likelihood for ANC utilization increased with increase in consciousness level of parents; which come from their education level, effect from income group (high socioeconomic status), mass media exposure (included paper/radio/television). Regional differential is significant (though with explaining small variation division); biological factor (age of mothers, birth order of index child) also showed significant effect on ANC utilization of Bangladeshi women. One of the major findings of current study is the notable effect of women's empowerment (namely freedom of movement autonomy and decision about health care) on ANC utilization of Bangladeshi women. This last prospect is quite remarkable for many developing countries (Woldemicael ${ }^{14}, 2009$ ); also the effect of labor force participation of mothers is notable on ANC utilization, which is a pooled factor of employment of mother along with involving in NGOs'.

From the findings of current study it may be recommended that, to enhance antenatal health care behavior of women, emphasis on women education should be given appropriate weight. This factor has a chain of effect on the other factors, too. It creates consciousness, impress women to get involved in income generating activities, also about health related problems associated with pregnancies. Additionally, huge campaigns will be effective to utilize antenatal health care services; special focus is needed on women in high risk groups such as women in higher parities and women from poor families.Still steps are needed to be taken to improve women empowerment level. The factors like improvements in women mobility outside home, access to health and family planning services and educational opportunities may play vital role in this circumstance.

\section{References}

1. World Health Organization, 2010. Trends in maternal mortality: 1990-2008. Geneva: WHO.

2. Nuraini, E., E. Parker, 2005. Improving knowledge of ANC among pregnancy women in field trial in Central Java Indonesia. Asia Pac J Public Health, 17(1), 3-8.

3. Carroli, G., C. Rooney, and J.Villar, 2001. How effective is antenatal care in preventing maternal mortality and serious morbidity? An overview of the evidence. Pediatric Perinatal Epidemiology, 15(1), 1-42.

4. Pickett, K. E., and M.Pearl, 2001. Multilevel analyses of neighborhood socioeconomic context and health outcomes: a critical review. J Epidemiol Community Health,55, 111-22.

5. Say, L., and R. Raine, 2007. A systematic review of inequalities in the use of maternal health care in developing countries: examining the scale of the problem and the importance of context. Bull World Health Organ, 85, 812-9.

6. Khatun, S., and M.Rahman, 2008. Quality of antenatal care and its dose-response relationship with birth weight in a maternal and child health training institute in Bangladesh. $J$ Biosoc Sci., 40(3), 321-337.

7. Anwar, I. et.A1., 2008. Inequity in maternal health-care services: evidence from home-based skilled-birth-attendant programmes in Bangladesh. Bull World Health Organ, 86(4), 252-259.

8. Pervin, J. et, al, 2012. Association of antenatal care with facility delivery and perinatal survival - a population-based study in Bangladesh. BMC Pregnancy Childbirth,12(1), 111.

9. Amin, R., S. A. Chowdhury, G. M. Kamal, and J. Chowdhury, 1989. Community health services and health care utilization in rural Bangladesh.SocSci Med, 29, 1343-1349.

10. Simkhada, B. et.Al., 2008. Factors affecting the utilization of antenatal care in developing countries: systematic review of the literature. Journal of Advanced Nursing,61(3), 244-260.

11. Islam, M. R., and J. O.Odland, 2011. Determinants of antenatal and postnatal care visits among Indigenous people in Bangladesh: a study of the Mru Community. Rural and Remote Health,11: 1672.

12. Choudhury, N, and S. M. Ahmed, 2011. Maternal care practices among the ultra poor households in rural Bangladesh: a qualitative exploratory study. BMC Pregnancy Childbirth,11, 15. 
13. Stephenson, R, and K. M.Elfstrom, 2012. Community Influences on Antenatal and Delivery Care in Bangladesh, Egypt, and Rwanda. Public Health Reports,127(1), 96-106.

14. Woldemicael, G., 2009. Women's autonomy and reproductive preferences in Eritrea. J BiosocSci,41(2), 161-81.

15. Dynes, M.et.Al., 2011. Home-based life saving skills in Matlab, Bangladesh: a process evaluation of a community-based maternal child health programme. Midwifery,27(1), 15-22.

16. Rahman, A. et, al., 2011. Effectiveness of an integrated approach to reduce perinatal mortality: recent experiences from Matlab, Bangladesh. BMC Publ Health,11(1), 914.
17. Akanda, M. A. S., 2010. Demand for antenatal care in Bangladesh: An application of Two-part Model.South Asian Journal of Population and Health, 3(1), 29-41.

18. Hair, J.F. et.Al., 1995. Multivariate Data Analysis with Reading. 4th ed. New Jersy: Prentice Hall.

19. Mardia, K.V, et al. (1980). Multivariate Analysis. London: Academic press. 
